\title{
Binding Preference of Anti-HEV Antibodies in Sera Collected in Algeria for Antigens Derived From HEV Genotype 1
}

\author{
Nouredine Behloul, ${ }^{1}$ Min Zhang, ${ }^{2}$ and Jihong Meng1, \\ ${ }^{1}$ Department of Microbiology and Immunology, Southeast University School of Medicine, Nanjing, China \\ ${ }^{2}$ Zhongda Hospital, School of Medicine, Southeast University, Nanjing, China \\ "Corresponding author: Jihong Meng, Department of Microbiology and Immunology, Southeast University School of Medicine, Nanjing, China. Tel/Fax: +86-2583272386, E-mail: \\ jihongmeng@163.com
}

Received 2015 December 22; Revised 2016 February 26; Accepted 2016 May 10.

\begin{abstract}
Background: Two hepatitis E virus (HEV) outbreaks occurred in Algeria (1979 - 1980 and 1987 - 1988). However, to date, no study on the prevalence of anti-HEV antibodies has been conducted in Algeria, and the genotype of the circulating strains remains unclear. Objectives: This study was conducted to investigate the presence of anti- HEV antibodies among outpatients and blood donors in three different hospitals in Northern Algeria and to determine the genotype of the circulating strains through the characterization of the immunoreactivity of anti-HEV antibodies.

Methods: A total of 590 blood samples ( 379 from blood donors and 211 from outpatients) were collected in three health facilities in Northern Algeria and assessed for anti-HEV antibodies using an in-house double-antigen sandwich immunoassay. HEV open reading frame 2 recombinant proteins p166 (aa 452 - 617) generated from the four HEV genotypes were used as antigens. The genotype of the strains circulating in Algeria was predicted by an indirect ELISA by assessing the anti-HEV antibodies in serially diluted positive sera using the different p166 proteins.

Results: Anti-HEV antibodies were detected in $20.17 \%$ of the samples. A significant correlation was found between the age of the subjects and the presence of anti-HEV antibodies $(\mathrm{P}<0.001)$. Among blood donors, $83(21.9 \%)$ were diagnosed positive for anti-HEV antibodies with two cases weakly positive for anti-HEV IgM antibodies. Moreover, $9.9 \%$ of the subjects aged less than 25 years old (born after the last HEV outbreak) were positive for anti-HEV antibodies. The indirect ELISA revealed that the anti-HEV antibodies within the positive sera reacted more strongly against the p166 antigens generated from genotype 1.

Conclusions: The present findings reveal a relatively high presence of anti-HEV IgGs and clearly indicate that HEV infection is still present in Northern Algeria. Further, the prediction of HEV genotype using different antigens generated from the different HEV genotypes shows that the causative strains are more likely to be of genotype 1 .
\end{abstract}

Keywords: Hepatitis E Virus, Algeria, HEV Genotype Prediction, Enzyme-Linked Immunosorbent Assay

\section{Background}

Hepatitis E virus (HEV) is an important cause of acute clinical hepatitis in endemic countries and can lead to detrimental prognostics, such as severe acute hepatitis, liver failure, chronicity in immunocompromised patients, and death in pregnant women $(1,2)$. Four HEV genotypes have been reported to infect humans. Genotypes 1 and 2 are strictly human, transmitted by fecal-oral route, and responsible for water-borne HEV outbreaks in Asia, Africa, and Central America. HEV genotypes 3 and 4 are found in swine and other animal species in many countries where direct and indirect zoonotic transmission in industrialized countries have been reported (3-6).

The disease is considered emerging in many parts of the world because of the increased awareness and availability of effective diagnostics. The HEV seroprevalence has been found to be elevated even in areas classified non- endemic (7). North Africa is a region classified as endemic for hepatitis E. For instance, half of the population aged above five years in Egypt is serologically positive for HEV (8), and high HEV seroprevalence was reported in Tunisia, Libya, and Morocco (9). Furthermore, two HEV outbreaks occurred in Algeria. The first one occurred in Mostaganem (Northwest Algeria) in 1980 and the second in Tanefdour (Northeast Algeria) in 1986 - 1987 (10, 11). Both epidemics were traced back to contaminated water sources, and the causative pathogen was HEV genotype 1 . Another outbreak of hepatitis non-A and non-B occurred in Medea (Northern Algeria) from October 1980 to January 1981, and it affected 788 people, mostly young adults, with a mortality rate of $100 \%$ in pregnant women (12). Although the causative pathogen in this latter outbreak was not identified, it was likely to be HEV given the circumstances of the occurrence and the development of the disease. 


\section{Objectives}

To date, no accurate estimates of the prevalence of HEV in Algeria are available. Moreover, no studies on HEV or anti-HEV antibodies have been conducted, and HEV infection is not investigated in the hospitals when assessing acute hepatitis. Therefore, this study aimed to investigate the presence of anti-HEV antibodies in Northern Algeria, determine the HEV genotype(s) of the circulating strains, and elucidate the contamination routes (zoonotic and/or water-borne).

\section{Methods}

\subsection{Study Population}

Sample size was calculated to be 517 based on an anticipated anti-HEV IgG rate of $15 \%$, a margin of error of $3 \%$, a confidence level of 95\%, and a population size of approximately 10,000 (information from the commune chiefs on the total population depending on the three health facilities). Therefore, the intended sample size was determined to be 590. The blood samples were collected from three hospitals in central Algeria: 379 samples from blood donors and 211 samples from outpatients. Sera were separated and stored at $-20^{\circ} \mathrm{C}$ until further analysis. At their convenience, the subjects were enrolled in the study from January to May 2014. The demographic characteristics of the study population are presented in Table 1 . This study was conducted in accordance with the national ethics regulation and was approved by the research ethics committee of Southeast University in Nanjing.

\subsection{Preparation of HEV P166 Antigens}

The truncated p166 capsid protein was generated from the amino acid position 452-617 of the open reading frame 2 of the following HEV strains: W01 (genotype 1, JX857689), Mexico-14 (genotype 2, M74506), US-1 (genotype 3, AF060668), and China-9829 (genotype 4, AY789225) strains, and expressed in Escherichia coli (13). Briefly, the polymerase chain reaction fragment encoding aa 452 617 of the HEV strains was inserted into the pET28a vectors (Novagen, Darmstadt, Germany). Then, the plasmids were used to transform competent E. coli BL21 (DE3) cells (Promega, Madison, USA). After the confirmation of the sequence of aa 452 - 617 in the plasmids by DNA sequencing, the gene expression was induced. The cells were pelleted and lysed after an incubation period and constant shaking. The suspension was clarified by centrifugation, and then the supernatant was loaded onto a column containing Ni-NTA super flow affinity resin. The column was washed, and the fusion proteins were eluted as described previously (14). The four p166 proteins were designated as p166W01, p166Mex, p166US, and p166Chn, and a mixture (p166mix) containing equal concentrations of each of the four p166 proteins was prepared.

\subsection{Detection of Anti-HEV Total Antibodies}

Sera were screened for the presence of anti-HEV antibodies with a high performance assay, namely, the inhouse sandwich enzyme immunoassay, according to Dong et al. (14). A double-antigen sandwich assay using the p166 proteins was adopted. Briefly, microplate wells were coated with His-p166 mix and incubated at room temperature overnight. Unbound antigens were washed with 10 mM phosphate-buffered saline containing 0.05\% Tween 20 (PBS-T). Then, undiluted test serum was added, and the plates were incubated at $37^{\circ} \mathrm{C}$ for 1 hour. After a washing step with PBS-T, the horseradish peroxidase (HRP)conjugated p166 mix was added, and the plates were incubated at $37^{\circ} \mathrm{C}$ for 1 hour. After washing, tetramethylbenzidine was added as substrate, and the plates were read using a kinetic microplate reader at a wavelength of $450 \mathrm{~nm}$. All sera were tested in duplicate, and a signal/cutoff (s/co) value of $\geq 1$ was considered a positive reaction.

\subsection{Detection of Anti-HEV IgM Antibodies}

The presence of anti-HEV IgM antibodies was also assessed as previously described (15). Briefly, the purified p166 proteins were used as antigens to coat microplate wells. After an incubation period of $2 \mathrm{~h}$ at $37^{\circ} \mathrm{C}$, followed by three washings with PBS containing 0.05\% Tween 20, test and control were distributed into wells and incubated for $1 \mathrm{~h}$ at $37^{\circ} \mathrm{C}$. After three washings, the HRP-conjugated goat anti-human IgM (KPL) was added to each well and incubated at $37^{\circ} \mathrm{C}$ for 1 hour. After a final washing, the colorimetric reactions were developed using tetramethylbenzidine substrate (Sigma) for 15 minutes at room temperature and stopped with $2 \mathrm{M} \mathrm{H}_{2} \mathrm{SO}_{4}$. The plates were read using a kinetic microplate reader at $450 \mathrm{~nm}$ wavelength.

\subsection{HEV Genotype Prediction by Assessment of Anti-HEV IgG in the Positive Sera}

An indirect ELISA was adopted to detect IgG antibodies in serially diluted positive sera. The 166 proteins generated from the four genotypes were used as antigens, and each p166 protein was used in a separate analysis as previously described (16). Briefly, the purified His-p166 proteins were used as antigens to coat microplate wells. After an incubation period of 2 hours at $37^{\circ} \mathrm{C}$, followed by three washings with PBS containing 0.05\% Tween 20, test and control sera serial dilutions (1: 200,1: 400,1: 800,1: 1600, 1: 3200, and 1: 6400) were distributed into wells and incubated for 
$1 \mathrm{~h}$ at $37^{\circ} \mathrm{C}$. After three washings, the HRP-conjugated goat anti-human IgG (KPL) was added to each well and incubated at $37^{\circ} \mathrm{C}$ for 1 hour. After a final washing, the colorimetric reactions were developed using tetramethylbenzidine substrate (Sigma) for 15 minutes at room temperature and stopped with $2 \mathrm{M} \mathrm{H}_{2} \mathrm{SO}_{4}$. The plates were read using a kinetic micro-plate reader at a wavelength of $450 \mathrm{~nm}$.

\subsection{Statistical Analysis}

Seropositivity rates were calculated and compared according to age group and gender. Differences were evaluated using logistic regression analysis and the chi-square test. $\mathrm{P}<0.05$ was considered statistically significant. For the cross-genotype neutralization assay, two-way ANOVA with Bonferroni posttest was performed using GraphPad Prism version 5.00 for Windows (GraphPad Software, San Diego, CA, USA).

\section{Results}

\subsection{Detection of Anti-HEV Antibodies}

The serological screening detected an overall seropositivity of $20.17 \%$ as shown in Table 1 . Although a slight difference was found in the prevalence rates between males and females (Table1), statistically no significant correlation was noted between HEV seroprevalence and subjects' gender $(\mathrm{P}=0.5)$.

Table 1 represents the number of positive cases by age group. Initially, the patients were grouped by an interval of 10 years. The results showed that majority of the positive cases were aged between 21 and 60 years old and that no positive case was found from 0 to 10 years old. However, this result must be taken with caution given the small number of sample in this group (only four). However, compared with the group of $\geq 70$ years, which also had a small number of sample $(\mathrm{n}=11)$, four positive cases were detected. To better appreciate these results, they are represented as percentages compared with the total number of sample in each age group. The groups of 21 - 30, 31 - 40, and 41 - 50 years almost had equal rates at $18.82 \%, 18.50 \%$, and $22.37 \%$, respectively, but these rates were significantly higher than that of the first group. The group of patients aged less than 20 years had the lowest rate (6.25\%).

The positivity rate continued to increase to reach a maximum of $29.76 \%$ in group 51 - 60 years to finally decrease to $25 \%$ in the last group ( $\geq 61$ years). Logistic regression analysis showed a significant correlation between age of the patients and presence of anti-HEV antibodies ( $P$ $=0.001$ ) as shown in Table 1 . Processing the results of the blood donors alone was important. Note that among the 379 blood donors (mean age 38.73, age range 18 - 65, 55.67\% are men), 83 (21.9\%) were diagnosed positive for anti-HEV antibodies, 37 of whom were women.

Testing the presence of anti-HEV IgM antibodies in all samples revealed only two weakly positive cases who were both blood donors (a 48-year-old woman and a 32-year-old man).

\subsection{Presence of Anti-HEVAntibodies in the Different Age Groups}

In a second step, the subjects were grouped into three age groups according to whether they were born before or after the 1987 - 1988 and 1979 - 1980 outbreaks. The results showed that $24.29 \%$ of the subjects aged over 36 years (born before the first outbreak of 1978) were positive for the presence of anti-HEV antibodies. This rate decreased to $17.4 \%$ in the subjects aged between 25 and 35 years (born after the 1978 outbreak and before the 1987 outbreak). The antiHEV antibody prevalence rate was only $9.9 \%$ for the subjects aged less than 25 years (born after the last outbreak). Statistically, a significant correlation was found between age and presence of anti-HEV antibodies $(\mathrm{P}=0.033)$.

\subsection{HEV Genotype Prediction by Assessing Anti-HEV IgG in Pos- itive Sera}

We previously assessed the immunoreactivity of antiHEV antibodies present in the serum sample collected from patients infected with different HEV genotypes (genotype 1 : $n=15$, genotype 3 : $n=12$, and genotype: $4 \mathrm{n}=17$ ) using p166 antigens generated from the four HEV genotypes (16). The sera were serially diluted, and the anti-HEV antibodies were detected by an indirect ELISA. The four p166 proteins were used as antigens, and each p166 antigen was used in a separate experiment. The results revealed that the immunoreactivity of anti-HEV antibodies raised against genotype 1 strains was stronger than that against the p166 antigens generated from genotypes 1 and 2 (p166W01 and p166Mex) and that against the p166 antigens generated from genotypes 3 and 4 (p166US and p166Chn). By contrast, the reaction of anti-HEV antibodies raised against the zoonotic genotypes 3 and 4 was more significant than that against the p166 antigens generated from genotypes 3 and 4 (p166US and p166Chn) as shown in Figure 1.

Moreover, we exploited this immunoreactivity difference for the prediction of the HEV genotypes in this serum panel collected in Algeria. As expected, the detection of anti-HEV IgG antibodies in the positive sera using the different p166 antigens generated from the different HEV genotypes revealed a variation of immunoreactivity (Figure 2). The IgG antibodies reacted strongly against p166W01 (generated from HEV genotype 1) at all dilution titers. These results showed the obvious effects of the antigen origin on the IgG-binding ability and suggested that 
Table 1. Prevalence of HEV Antibodies in Relation to Gender (A) and Age (B) of Subjects and the Logistic Regression Analysis Results (C)

\begin{tabular}{|c|c|c|c|c|}
\hline & \multicolumn{4}{|c|}{ A. Anti-HEV Antibodies Prevalence by Gender } \\
\hline & Samples, No. (\%) & Age, Mean (Range) & Positive, No. (\%) & Negative, No. (\%) \\
\hline Female & $289(48.98)$ & $38.87(6-78)$ & $55(19.03)$ & $234(80.97)$ \\
\hline Male & $301(51.02)$ & $39.86(9-83)$ & $64(21.26)$ & $237(78.74)$ \\
\hline \multirow[t]{2}{*}{ Overall } & $590(100)$ & $39.365(6-83)$ & $119(20.17)$ & $471(79.83)$ \\
\hline & \multicolumn{4}{|c|}{ B. Anti-HEV Antibodies prevalence by Age Group } \\
\hline Age group, y & \multicolumn{2}{|r|}{ Total } & Positive, No. (\%) & Negative, No. (\%) \\
\hline $0-10$ & \multicolumn{2}{|r|}{4} & $0(0.00)$ & $4(100.00)$ \\
\hline $11-20$ & \multicolumn{2}{|r|}{60} & $4(6.67)$ & $56(93.33)$ \\
\hline $21-30$ & \multicolumn{2}{|r|}{85} & $16(18.82)$ & $69(81.18)$ \\
\hline $31-40$ & \multicolumn{2}{|r|}{173} & $32(18.50)$ & $141(81.50)$ \\
\hline $41-50$ & \multicolumn{2}{|r|}{152} & $34(22.37)$ & $118(77.63)$ \\
\hline $51-60$ & \multicolumn{2}{|r|}{84} & $25(29.76)$ & $59(70.24)$ \\
\hline $61-70$ & \multicolumn{2}{|r|}{21} & $4(19.05)$ & $17(80.95)$ \\
\hline$\geq 71$ & \multicolumn{2}{|r|}{11} & $4(36.36)$ & $7(63.64)$ \\
\hline \multirow[t]{3}{*}{ Overall } & \multicolumn{2}{|r|}{590} & $119(20.17)$ & $471(79.83)$ \\
\hline & \multicolumn{4}{|c|}{ C. Logistic Regression Analysis } \\
\hline & \multicolumn{2}{|c|}{ Odds Ratio (95\% CI) } & PValue & Chi Square test P Value \\
\hline Gender & \multicolumn{2}{|c|}{$0.926(0.619-1.388)$} & 0.711 & 0.500 \\
\hline Age & \multicolumn{2}{|c|}{$1.025(1.010-1.040)$} & 0.001 & 0.033 \\
\hline
\end{tabular}

the IgGs were more likely to be raised against an HEV genotype 1 strain (Figure 2).

\section{Discussion}

To our knowledge, this study is the first to determine the presence and immunoreactivity of anti-HEV antibodies in Northern Algeria and revealed a positivity rate of $20.17 \%$. This prevalence is higher than those of the countries on the northern side of the Mediterranean Sea, such as France and Italy $(17,18)$, but is relatively lower than those of neighboring countries on the southern side. In Egypt, the prevalence of anti-HEV antibodies reached $84.3 \%$ in pregnant women, $67.6 \%$ in rural areas, $56.4 \%$ in semi-urban areas, and $45.3 \%$ in blood donors (19-21). In Morocco, the prevalence is $8.5 \%$ among blood donors (22). In Tunisia, the seroprevalence of HEV is $46 \%$ in healthy people, $22 \%$ in blood donors, and $12 \%$ in pregnant women $(23,24)$. However, these results should be taken with caution because of the small number of subjects included in these studies.

In the present study, no significant correlation was found between gender and presence of anti-HEV antibodies, whereas a significant difference was found in seroprevalence among the different age groups. These results are similar to those previously reported in other studies conducted in various countries (25-27). This similarity is probably due to the comparable exposure of both sexes to the virus sources. However, exposure time is long in the elderly, and this long exposure increases the chances of contracting the virus, thus explaining the difference in HEV prevalence among the different age groups. The presence of anti-HEV antibodies in people under 25 years (9.9\%) and the two cases that were weakly positive for anti-HEV IgM contradicted the exposure to virus during the last outbreaks (1979-1980 and 1987-1988). These circumstances explain the results and indicate clearly that HEV infection is still present in Algeria.

Several strains of genotype 3 were isolated from humans and animals across different continents, where they cause sporadic cases mainly after the consumption of undercooked swine products. Several studies reported the isolation of HEV from several other animal species (2832). Except in swine, deer, rabbits, and mongooses, viral RNA has not been detected in other animal species. The distribution of genotype 3 and its dispersion throughout the world (33) raises the question of its presence in Algeria. However, Algeria, which is a Muslim country, has no swine consumption and breeding, thus making the pres- 
A

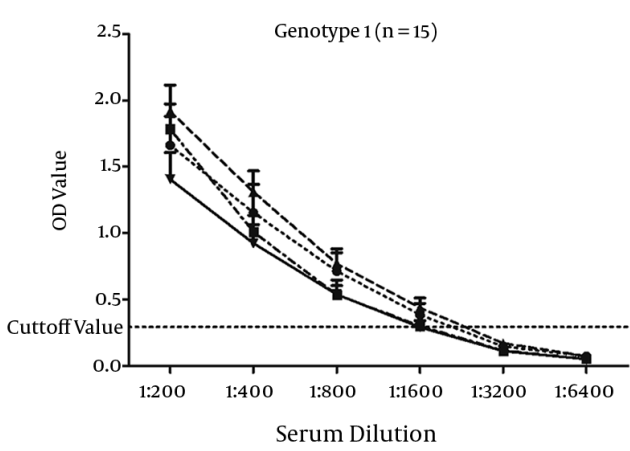

C

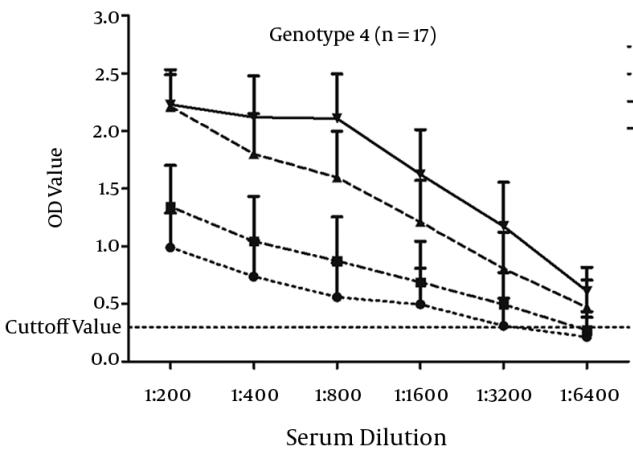

B
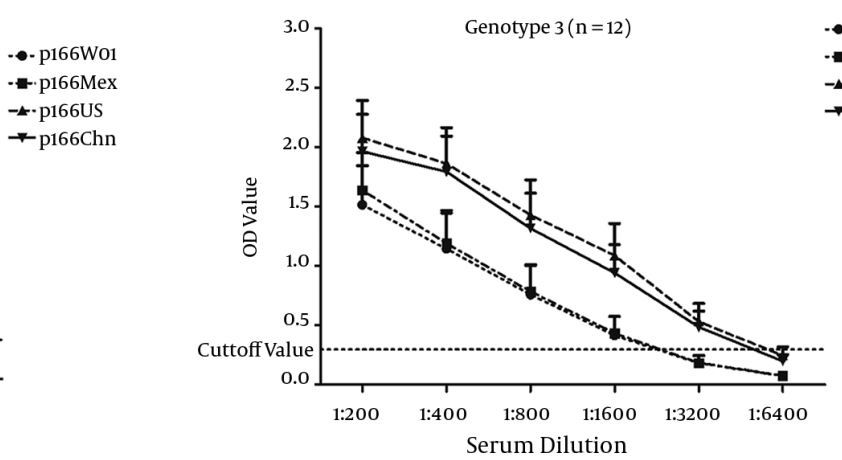

D

\begin{tabular}{|c|c|c|c|c|c|c|c|}
\hline \multirow[b]{3}{*}{ pl66W01 Vs. } & \multirow[b]{3}{*}{ pl66Mex } & \multicolumn{5}{|c|}{ Genotype 1} & \multirow{3}{*}{$\begin{array}{c}1: 6400 \\
\text { ns }\end{array}$} \\
\hline & & $1: 200$ & $1: 400$ & $1: 800$ & $1: 1600$ & $1: 3200$ & \\
\hline & & ns & ns & ns & ns & ns & \\
\hline pl66W01 Vs. & pl66US & $*$ & ns & ns & ns & ns & ns \\
\hline p166W01 Vs. & p166Chn & * & * & ns & ns & ns & ns \\
\hline pl66Mex Vs. & p166US & ns & $* *$ & * & ns & ns & ns \\
\hline p166Mex Vs. & p166 Chn & $* * *$ & ns & ns & ns & ns & ns \\
\hline \multirow[t]{3}{*}{ pl66US Vs. } & p166Chn & $* * *$ & $* * *$ & $*$ & ns & ns & ns \\
\hline & \multicolumn{7}{|c|}{ Genotype 3} \\
\hline & & $1: 200$ & $1: 400$ & $1: 800$ & $1: 1600$ & $1: 3200$ & $1: 6400$ \\
\hline pl66W01 Vs. & pl66Mex & ns & ns & $\mathrm{ns}$ & ns & ns & ns \\
\hline pl66W01 Vs. & p166US & $* * *$ & $* * *$ & $* * *$ & $* * *$ & ** & ns \\
\hline pl66W01 Vs. & p166Chn & $* * *$ & $* * *$ & $* * *$ & $* * *$ & * & ns \\
\hline p166Mex Vs. & p166US & $* * *$ & $* * *$ & $* * *$ & $* * *$ & ** & ns \\
\hline p166Mex Vs. & p166 Chn & $*$ & $* * *$ & $* * *$ & $* * *$ & * & ns \\
\hline \multirow[t]{3}{*}{ pl66US Vs. } & p166Chn & ns & ns & ns & ns & ns & ns \\
\hline & \multicolumn{7}{|c|}{ Genotype 4} \\
\hline & & $1: 200$ & $1: 400$ & $1: 800$ & $1: 1600$ & $1: 3200$ & $1: 6400$ \\
\hline pl66W01 Vs. & p166Mex & ns & ns & ns & ns & ns & ns \\
\hline p166W01 Vs. & p166US & $* * *$ & $* *$ & $* *$ & ns & ns & ns \\
\hline pl66W01 Vs. & p166Chn & $* * *$ & $* * *$ & $* * *$ & $* * *$ & * & ns \\
\hline pl66Mex Vs. & p166US & $*$ & $*$ & ns & ns & ns & ns \\
\hline p166Mex Vs. & p166Chn & $* *$ & $* * *$ & $* * *$ & $* *$ & ns & ns \\
\hline pl66US Vs. & $\mathrm{p} 166 \mathrm{Chn}$ & ns & ns & ns & ns & ns & ns \\
\hline
\end{tabular}

A, Sera of patients infected by HEV genotype 1 strains; B, Sera of patients infected by HEV genotype 3 strains; C, Sera of patients infected by HEV genotype 4 strains; D, Bonferroni multiple comparison test results. Each point represents mean $\pm S D ;{ }^{*} \mathrm{P}<0.05{ }^{* *} \mathrm{P}<0.01$ and ${ }^{* * *} \mathrm{P}<0.001(16)$.

ence of genotype 3 unlikely. In this study, only two cases were weakly positive for anti-HEV IgM antibodies. According to (34), viral RNA is no longer detectable at such a low rate of IgM antibodies. To predict the genotype of the causative strain that infected the subjects, we exploited the immunoreactivity difference among the p166 proteins generated from the four genotypes as reported previously (16). We showed that the IgG-binding ability is significantly stronger in the presence of antigens generated from the same genotype than from the genotype they were raised against. Using the same approach in this study, when the IgG-positive sera were assessed by different p166 proteins, the antibodies showed a stronger immunoreactivity against p166W01, which was generated from a genotype 1 strain. Moreover, for the HEV outbreaks that occurred in Algeria (1979 - 1980 and 1987 - 1988), the isolated virus belonged to HEV genotype 1 , which contaminated the water sources after a period of intense rain $(10,11)$. Therefore, given the present results and the available history of HEV in Algeria, the presence of genotype $1 \mathrm{HEV}$ is clearly the most likely reason, and this genotype $1 \mathrm{strain}(\mathrm{s})$ still causes sporadic cases.

Recently, research on hepatitis E has been directed to investigate the risk of HEV transmission via blood transfusions. Therefore, several studies on the seroprevalence of hepatitis E in blood donors were conducted (35-37). Although the positivity rates for anti-HEV IgM antibodies were relatively low, several cases of post-transfusion infection were reported (38-40). In this context, our study reveals a relatively high seroprevalence of anti-HEV antibodies (21.9\%) among blood donors, and only two cases weakly positive for anti-HEV IgM antibodies as discussed above were found. The accumulated data on this topic demonstrate a potential transfusion-associated risk. Given the high mortality rates in pregnant women and immunecompromised patients, detrimental effects will occur if 
Figure 2. Prediction of HEV Genotype in the IgG-Positive Sera $(n=30)$ by an Indirect ELISA

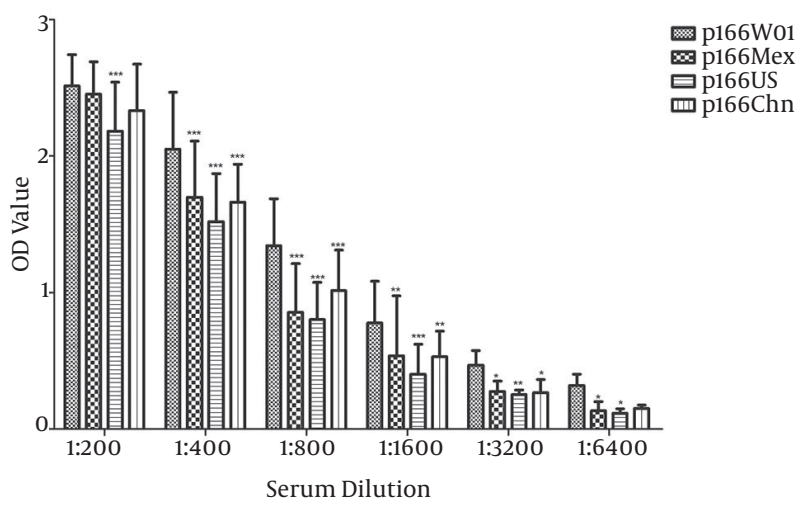

The sera were serially diluted, and the anti-HEV IgG antibodies were assessed using the different p166 antigens. Each p166 antigen was used in a separate experiment. *, ${ }^{* *},{ }^{* * *}=\mathrm{P}<0.05,0.01,0.001$ when compared with p166W01.

these patients receive HEV-contaminated blood products. However, making the screening of donated blood for the presence of HEV as a mandatory test is still early, and more detailed investigations are required especially in endemic areas.

In conclusion, we presented a new approach for the prediction of the genotype of HEV strains circulating in a given region in seroprevalence studies using different antigens generated from the four genotypes. This pilot study on the field application of this method revealed that the sera positive for anti-HEV antibodies presence reacted strongly against the antigens derived from HEV genotype 1. This finding indicates that hepatitis E in Northern Algeria is most likely caused by genotype 1 strains. Moreover, this study also revealed a relatively high seroprevalence of antiHEV antibodies within the targeted population in Northern Algeria. Therefore, to prevent future outbreaks, the management strategy of Algerian clinicians in assessing acute hepatitis requires an urgent re-evaluation. Finally, this study raises several issues that require further investigation: assess the prevalence and incidence of HEV infection throughout the Algerian territory, identify the risk factors other than age (e.g., socioeconomic condition, working in animal breeding, working in the health sector, and co-infection with other pathogens), and evaluate the risk of transmission via blood donation.

\section{Acknowledgments}

We acknowledge the funding support from Nanjing science and technology project fund (Grant: 201402002).
We would like to thank Abdenour Behloul, Adlane Benhamouche, and Houda Boukhrissa for their assistance during the sample collection.

\section{Footnote}

Authors' Contribution: Study conception and design: Jihong Meng and Nouredine Behloul; acquisition of data: Nouredine Behloul; analysis and interpretation of data: Jihong Meng and Nouredine Behloul; drafting of manuscript: Nouredine Behloul; critical revision: Min Zhang and Jihong Meng.

\section{References}

1. Zhou X, de Man RA, de Knegt RJ, Metselaar HJ, Peppelenbosch MP, Pan Q. Epidemiology and management of chronic hepatitis $\mathrm{E}$ infection in solid organ transplantation: a comprehensive literature review. Rev Med Virol. 2013;23(5):295-304. doi: 10.1002/rmv.1751. [PubMed: 23813631].

2. Mushahwar IK. Hepatitis E virus: molecular virology, clinical features, diagnosis, transmission, epidemiology, and prevention. J Med Virol. 2008;80(4):646-58. doi: 10.1002/jmv.21116. [PubMed:18297720].

3. Arends JE, Ghisetti V, Irving W, Dalton HR, Izopet J, Hoepelman AI, et al. Hepatitis E: An emerging infection in high income countries. JClin Virol. 2014;59(2):81-8. doi: 10.1016/j.jcv.2013.11.013. [PubMed: 24388207].

4. Kamar N, Bendall R, Legrand-Abravanel F, Xia NS, Ijaz S, Izopet J, et al. Hepatitis E. Lancet. 2012;379(9835):2477-88. doi: 10.1016/S01406736(11)61849-7. [PubMed: 22549046].

5. Meng XJ. From barnyard to food table: the omnipresence of hepatitis $\mathrm{E}$ virus and risk for zoonotic infection and food safety. Virus Res. 2011;161(1):23-30. doi: 10.1016/j.virusres.2011.01.016. [PubMed: 21316404].

6. Li TC, Chijiwa K, Sera N, Ishibashi T, Etoh Y, Shinohara Y, et al. Hepatitis E virus transmission from wild boar meat. Emerg Infect Dis 2005;11(12):1958-60. doi: 10.3201/eid1112.051041. [PubMed: 16485490].

7. Thomas DL, Yarbough PO, Vlahov D, Tsarev SA, Nelson KE, Saah AJ, et al. Seroreactivity to hepatitis E virus in areas where the disease is not endemic. J Clin Microbiol. 1997;35(5):1244-7. [PubMed: 9114415].

8. WHO . Hepatitis E 2014. Available from: http://www.who.int/ mediacentre/factsheets/fs280/en/.

9. Kamal SM, Mahmoud S, Hafez T, El-Fouly R. Viral hepatitis a to e in South mediterranean countries. Mediterr J Hematol Infect Dis. 2010;2(1):2010001. doi: 10.4084/MJHID.2010.001. [PubMed: 21415943].

10. Grandadam M, Tebbal S, Caron M, Siriwardana M, Larouze B, Koeck JL et al. Evidence for hepatitis E virus quasispecies. J Gen Virol. 2004;85(Pt 11):3189-94. doi:10.1099/vir.0.80248-0. [PubMed: 15483231].

11. van Cuyck-Gandre H, Zhang HY, Tsarev SA, Clements NJ, Cohen SJ, Caudill JD, et al. Characterization of hepatitis E virus (HEV) from Algeria and Chad by partial genome sequence. J Med Virol. 1997;53(4):3407. [PubMed: 9407381].

12. Belabbes EH, Bouguermouh A, Benatallah A, Illoul G. Epidemic non-A non-B viral hepatitis in Algeria: strong evidence for its spreading by water. J Med Virol. 1985;16(3):257-63. [PubMed: 3928807].

13. Zhang H, Dai X, Shan X, Meng J. Characterization of antigenic epitopes of the ORF2 protein from hepatitis E virus genotype 4 Virus Res. 2009;142(1-2):140-3. doi: 10.1016/j.virusres.2009.02.002. [PubMed: 19428747].

14. Dong C, Meng J, Dai X, Liang JH, Feagins AR, Meng XJ, et al. Restricted enzooticity of hepatitis E virus genotypes 1 to 4 in the United States. $J$ Clin Microbiol. 2011;49(12):4164-72. doi:10.1128/JCM.05481-11. [PubMed: 21998412]. 
15. Dong C, Dai X, Liang J, Dong M, Meng J. Seroprevalence of hepatitis e virus varies considerably among chinese provinces. Hepat Mon 2012;12(6):386-90. doi: 10.5812/hepatmon.6194. [PubMed: 22879828].

16. Behloul N, Wen J, Dai X, Dong C, Meng J. Antigenic composition and immunoreactivity differences between HEV recombinant capsid proteins generated from different genotypes. Infect Genet Evol. 2015;34:211-20. doi: 10.1016/j.meegid.2015.06.026. [PubMed: 26122075].

17. Rapicetta M, Monarca R, Kondili LA, Chionne P, Madonna E, Madeddu $\mathrm{G}$, et al. Hepatitis E virus and hepatitis A virus exposures in an apparently healthy high-risk population in Italy. Infection. 2013;41(1):69-76 doi: 10.1007/s15010-012-0385-8. [PubMed: 23264095].

18. Boutrouille A, Bakkali-Kassimi L, Cruciere C, Pavio N. Prevalence of anti-hepatitis E virus antibodies in French blood donors. J Clin Microbiol. 2007;45(6):2009-10. doi: 10.1128/JCM.00235-07. [PubMed. 17460057].

19. Stoszek SK, Abdel-Hamid M, Saleh DA, El Kafrawy S, Narooz S, Hawash $Y$, et al. High prevalence of hepatitis E antibodies in pregnant Egyp tian women. Trans $R$ Soc Trop Med Hyg. 2006;100(2):95-101. doi 10.1016/j.trstmh.2004.12.005. [PubMed:16257426].

20. Fix AD, Abdel-Hamid M, Purcell RH, Shehata MH, Abdel-Aziz F, Mikhail $\mathrm{N}$, et al. Prevalence of antibodies to hepatitis E in two rural Egyp tian communities. Am J Trop Med Hyg. 2000;62(4):519-23. [PubMed: 11220771].

21. Darwish MA, Faris R, Clemens JD, Rao MR, Edelman R. High seroprevalence of hepatitis A, B, C, and E viruses in residents in an Egyptian village in The Nile Delta: a pilot study. Am JTrop Med Hyg. 1996;54(6):5548. [PubMed: 8686770].

22. Aamoum A, Baghad N, Boutayeb H, Benchemsi N. [Seroprevalence of hepatitis E virus in Casablanca]. Med Mal Infect. 2004;34(10):491-2. [PubMed: 15747476].

23. Hannachi N, Hidar S, Harrabi I, Mhalla S, Marzouk M, Ghzel H, et al. [Seroprevalence and risk factors of hepatitis E among pregnant women in central Tunisia]. Pathol Biol (Paris). 2011;59(5):115-8. doi: 10.1016/j.patbio.2009.06.004. [PubMed: 19896306]

24. Safer L, Ben Chaabene N, Melki W, Saffar H. [Epidemiology of viral hepatitis in Tunisia]. Rev Epidemiol Sante Publique. 2006;54(4):377-80. [PubMed: 17088701].

25. Strakova P, Kriz B, Rudolf I, Hubalek Z. Seroprevalence study of hepatitis E virus infection in two districts of the Czech Republic. Epidemiologie, mikrobiologie, imunologie : casopis Spolecnosti pro epidemiologii a mikrobiologii Ceske lekarske spolecnosti. JE Purkyne. 2014;63(2):92-4

26. Alvarado-Esquivel C, Sanchez-Anguiano LF, Hernandez-Tinoco J. Seroepidemiology of hepatitis e virus infection in general population in rural durango, Mexico. Hepat Mon. 2014;14(6):16876.

27. Ditah I, Ditah F, Devaki P, Ditah C, Kamath PS, Charlton M. Current epidemiology of hepatitis E virus infection in the United States: low seroprevalence in the National Health and Nutrition Evaluation Survey. Hepatology. 2014;60(3):815-22. doi: 10.1002/hep.27219. [PubMed
24824965].

28. Wang S, Dong C, Dai X, Cheng X, Liang J, Dong M, et al. Hepatitis E virus isolated from rabbits is genetically heterogeneous but with very similar antigenicity to human HEV.J Med Virol. 2013;85(4):627-35. doi: 10.1002/jmv.23504. [PubMed: 23364756]

29. El-Tras WF, Tayel AA, El-Kady NN. Seroprevalence of hepatitis E virus in humans and geographically matched food animals in Egypt. Zoonoses Public Health. 2013;60(3):244-51. doi: 10.1111/j.18632378.2012.01516.x. [PubMed: 22812407].

30. Shukla P, Chauhan UK, Naik S, Anderson D, Aggarwal R. Hepatitis E virus infection among animals in northern India: an unlikely source of human disease. J Viral Hepat. 2007;14(5):310-7. doi: 10.1111/j.13652893.2006.00815.x. [PubMed: 17439520].

31. Wang YC, Zhang HY, Xia NS, Peng G, Lan HY, Zhuang H, et al. Prevalence, isolation, and partial sequence analysis of hepatitis $\mathrm{E}$ virus from domestic animals in China. J Med Virol. 2002;67(4):516-21. doi: 10.1002/jmv.10131. [PubMed: 12115997].

32. Arankalle VA, Joshi MV, Kulkarni AM, Gandhe SS, Chobe LP, Rautmare SS, et al. Prevalence of anti-hepatitis E virus antibodies in different Indian animal species. JViral Hepat. 2001;8(3):223-7. [PubMed:11380801].

33. Marulier FM. Hepatitis E From Zoonotic Origin. France: Paris-Est Créteil Val de Marne; 2009.

34. Dalton HR, Bendall R, Ijaz S, Banks M. Hepatitis E: an emerging infection in developed countries. Lancet Infect Dis. 2008;8(11):698-709. doi: 10.1016/S1473-3099(08)70255-X. [PubMed:18992406].

35. Zhuang W, Ding X, Lyu C, Xiang L, Teng H, Li J. Hepatitis E virus seroprevalence among blood donors in Jiangsu Province, East China. Int J Infect Dis. 2014;26:9-11.

36. Gajjar MD, Bhatnagar NM, Sonani RV, Gupta S, Patel T. Hepatitis E seroprevalence among blood donors: A pilot study from Western India. Asian J Transfus Sci. 2014;8(1):29-31. doi: 10.4103/0973-6247.126685. [PubMed: 24678170].

37. Pittaras T, Valsami S, Mavrouli M, Kapsimali V, Tsakris A, Politou M. Seroprevalence of hepatitis E virus in blood donors in Greece. Vox Sang. 2014;106(4):387. doi: 10.1111/vox.12122. [PubMed: 24387713].

38. Matsui T, Kang JH, Matsubayashi K, Yamazaki H, Nagai K, Sakata H. . A rare case of transfusion-transmitted hepatitis $\mathrm{E}$ from the blood of a donor infected with the hepatitis E virus genotype 3 indigenous to Japan: Viral dynamics from onset to recovery. Hepatol Res. 2014.

39. Matsubayashi K, Kang JH, Sakata H, Takahashi K, Shindo M, Kato M, et al. A case of transfusion-transmitted hepatitis E caused by blood from a donor infected with hepatitis E virus via zoonotic food-borne route. Transfusion. 2008;48(7):1368-75. doi: 10.1111/j.1537-2995.2008.01722.x. [PubMed: 18651907].

40. Mitsui T, Tsukamoto Y, Yamazaki C, Masuko K, Tsuda F, Takahashi M, et al. Prevalence of hepatitis E virus infection among hemodialysis patients in Japan: evidence for infection with a genotype $3 \mathrm{HEV}$ by blood transfusion. J Med Virol. 2004;74(4):563-72. doi: 10.1002/jmv.20215. [PubMed: 15484278]. 